\title{
Urinary System Findings Supplemental Qualifiers Dataset
}

National Cancer Institute

\section{Source}

National Cancer Institute. Urinary System Findings Supplemental Qualifiers Dataset. NCI

Thesaurus. Code C147267.

A dataset containing supplemental information, specifically non-standard variables, to parent records in the urinary system findings domain. 